\title{
STUDENTS' PREFERENCES TOWARD CORRECTIVE FEEDBACKS ON STUDENTS' ORAL PRODUCTION
}

\author{
Rinda Fitriana \\ Widya Gama Mahakam University \\ rinda1_rafa@gmail.com \\ Bibit Suhatmady \\ Mulawarman University \\ suhatmady@yahoo.com \\ Iwan Setiawan \\ Mulawarman University \\ iwansetiawan_s2bingunmul@yahoo.com
}

\begin{abstract}
This study aimed on revealing students' preference on types of corrective feedback given by their English teacher as well as their reason. The study was conducted in a vocational school in Samarinda. Data collection was done by means of observation, interview and questionnaire. The observation was done for three meetings each in two different level of English proficiency classes (high and low) and ten students from the observed classes were interviewed. Moreover, the questionnaires were administered to 196 out of 385 students from all classes of twelfth grade. Furthermore, the result of this study revealed that the students preferred to have Explicit, Meta-Linguistic Clue and Elicitation corrective feedback. However, there was mismatch between students' preference on the expected type corrective feedback (Explicit) and the teacher's corrective feedback (Recast). The students' preference on explicit corrective feedback was based on the reason that it provided answer and explanation on the correct version of the corrected oral production. The students' preference on Meta-linguistic Clue and Elicitation corrective feedback were because these feedbacks activated their knowledge and generated students' thinking to discover the correct version.
\end{abstract}

Keywords: students' preferences, corrective feedbacks, and mismatch

\section{INTRODUCTION}

Students who learn English as foreign language must do a lot of errors during the learning process. Teachers have responsibility to repair the errors in order to prevent them doing the same errors at another occasion (Ur, 1996) and make them closer to acquiring the target language (Selinker in Ur, 1996). In other side, they also need to maintain students' motivation in English. Correcting students' errors sometimes lead students to be demotivated. Inappropriate correction or negative feedback from teacher might influence student's anxiety, which means it might cause fossilization (Vigil and Oller in Brown, 2000; Rahimi \& Dastjerdi 2012) and it can cause student blanking on to say something in the target language (Ortega, 2009). Therefore, giving correction to students' errors should meet their expectation 
(Odalejo, 1993; Katayama, 2007), so that, they still can repair their errors and improve their English, in way of correction that they can accept. Since, students expect feedback from the teachers every time they try to produce their English. For them, feedback is one way to make them closer to English and finally acquire it as their second language. For that reason, this study aims to answer research questions as follows: (1) What are students' preferences toward corrective feedbacks on their oral productions?; (2) Why did the students in prefer to have particular types of corrective feedback?

\section{Corrective Feedback}

The goal of giving corrective feedback is to repair student's error. Harmer (2001) emphasized that to react on errors which occurred during oral work, teacher needs to consider the stage of the lesson, the activity, the type of error made, and the particular students who are making that error. He also added that, in treating students' errors, teacher also needs to consider the purpose of the lesson, whether it emphasizes on the accuracy (such as activity with a piece of grammar, a pronunciation exercise, or vocabulary enhancement) or it focuses on fluency which let students to use the target language as fluent as possible. Therefore, the purpose of the lesson will influence teacher to provide appropriate types of correction for students who making errors. For example, when the purpose is to make students use English fluently, then teacher is not expected to use immediate corrective feedback. Since, the student may accept negative affective feedback which leads her/him to inhibit in trying communicating the idea in English. In short, negative feedback or inappropriate corrective feedback may affect students to stop learning and cause fossilization.

After a teacher decided the quantity, the timing and the corrector of errors should be corrected, teacher should decide what treatment to be used or we called the treatment as teacher's correction. There are several types of error correction which emphasized on the timing (immediate or delay) and the manner (implicit or explicit). In this section, we provided types of correction that used by Chaudron (1988); Lyster \& Ranta (1997); Méndez et al. (2010); Méndez \& Cruz (2012); and Harmer (2001). There are at least thirty types of correction that Chaudron proposed (see Appendix 1). It seems the model that Chaudron in Allwright \& Bailey (1991) described the error treatment process in detail. However, we only took the 'transfer' and 'interruption' type of correction to be added in her instruments for the focus of preferences on type of corrective feedback, since, they are the common type that used by teachers whom we ever met for correction. Moreover, types of correction that Lyster \& Ranta (1997); Méndez et al. (2010); Méndez \& Cruz (2012) developed similar types with

Script Journal Volume 1, Issue 1, April 2016 || ISSN 2477-1880 || E-ISSN 2502-6623 http://jurnal.fkip-uwgm.ac.id/index.php/Script 
Chaudron, but it is more concise. Méndez et al. (2010) used the types of correction that developed by Lyster \& Ranta (1997) and added Yao's in Méndez et al. (2010); Méndez \& Cruz (2012) interruption and body language as corrective feedback.

Lyster \& Ranta (1997) found six types of corrective feedback. First is Explicit Correction. This type describes teacher providing the correct version of the error by saying "Oh, you mean...," "You should say..." to indicate student's error clearly. Recast is the second type of corrective feedback. Here, teacher paraphrases all or part of a student's error. If it relates to Chaudron's theory, it is similar to the categories of "repetition with change" and "repetition with change and emphasis". Lyster \& Ranta (1997) also added that L1 translation is included in recast. Moreover, Clarification Request is the third type of corrective feedback. In this type, teacher uses phrases like "Pardon me" to require student self-correct the error. The next type is Meta-linguistic feedback. It contains comments, information, or questions related to the correct version implicitly.

Usually, teacher will use question like "Can you find your error?" or statement like "No, no X", or just "No". Elicitation is the fifth type of corrective feedback. It refers to three teacher's techniques to make student provide the correct form of the error. The techniques are 1) strategically pausing to allow student continue teacher's sentence with the correct form, 2) using question like "How do we say X in English?", and 3) asking students to reformulate their utterances occasionally. The last type is repetition. In this type, teacher repeats student's error and isolating it by changing the intonation to emphasize the error location.

In research that was done by Lyster \& Ranta (1997), the examples of each types of corrective feedback is in French. Since, they investigated French immersion classrooms. We had difficulty to comprehend those examples for these types of corrective feedback. Therefore, we adapted examples that Méndez et al. (2010) developed from Lyster \& Ranta (1997) types of corrective feedback. Méndez et al. (2010) divided the correction into two; implicit and explicit corrective feedback. Explicit corrective feedback refers to the condition when teacher tell student that s/he made error clearly as well as provide the correct version by using phrases like "You should say..." and followed by explanation. Meanwhile, they defined implicit corrective feedback as correction that given by teacher that is done indirectly, in order to push student self-correct their own errors. However, sometimes this type of correction leads students to confusion. There are seven types of corrective feedback that summarized by Méndez et al. (2010). They are: (1) Recast. Teacher repeats student's error by providing the correct version. In recast type, usually teacher does not use phrases

Script Journal Volume 1, Issue 1, April 2016 || ISSN 2477-1880 || E-ISSN 2502-6623 http://jurnal.fkip-uwgm.ac.id/index.php/Script 
such as "You mean..." or "you should say..." Lyster \& Ranta (1997) in Méndez et al. (2010); (2) Clarification request. Teacher usually asks the student to repeat the deviant utterances with intention student enable to self-correct. It focuses on comprehensibility or accuracy, or both. Usually, teacher use phrases "Pardon me", "Excuse me", and "I'm sorry". Lyster \& Ranta (1997) in Méndez et al. (2010); (3) Metalinguistic feedback. This type allows teacher to provide information or questions link to the error that student made without correct it explicitly Lyster \& Ranta (1997) in Méndez et al. (2010); (4) Elicitation. Lyster \& Ranta (1997) in Méndez et al. (2010) described this type of correction as the condition where a sentence is provided by teacher and s/he tactically stop to make student continue it with the correct form, then, if the students still give wrong answer, s/he comments like "No, not that. It's a..." or the error is repeated; (5) Repetition of error. The learner's error is repeated in isolation. Usually, teacher's intonation is adjusted to emphasize the error. Lyster \& Ranta (1997) in Méndez et al. (2010); (6) Interruption. Before student completed his or her sentence, teacher corrects the error directly. It can be said as immediate corrective feedback (Yao in Méndez et al., 2010); (7) Body Language. Yao in Méndez et al. (2010)) described that teacher uses his/her facial expression (e.g.: rising eyebrows) or body movement (e.g.: move her/his head) to tell that the student has made error and is expected to self-correct.

Moreover, Méndez \& Cruz (2012) called these types of corrective feedback as types of oral corrective feedback strategies. They summarized these types from Ween in Méndez \& Cruz (2012) and Yao in Méndez \& Cruz (2012). They classified these types into two; 1) correct form is provided and 2) correct form is elicited. Actually, they types of corrective feedback that they proposed were similar to Lyster \& Ranta (1997). In Méndez \& Cruz (2012) research, types of corrective feedback such as recast, explicit correction and explicit correction with meta-linguistic explanation belong to the category of 'correct form is provided'. Meanwhile, corrective feedback types such as repetition, elicitation, metalinguistic cue, body language and clarification request refer to the category of 'correct form is elicited'.

Reviewing the types of correction that Chaudron (1988); Méndez et al. (2010); and Méndez \& Cruz (2012) summarized, we assumed that these types of correction are actually used in the classroom, just, perhaps teachers do not know the names of the correction. It is happened because teachers (includes we) intuitively do the correction without referring the correction they give to the theory or previous research findings. Therefore, this issue became one of reason that forms the background of this study. It aimed to find out whether the

Script Journal Volume 1, Issue 1, April 2016 || ISSN 2477-1880 || E-ISSN 2502-6623 http://jurnal.fkip-uwgm.ac.id/index.php/Script 
correction that teachers have given to students can be proved theoretically effective or not effective to be use.

The explanation of various kinds of corrective feedback above underlain the construction of instruments (i.e.: questionnaires, interview guide, and observation guide) in this study. We combined Chaudron's model (i.e.: transfer, interruption), Lyster \& Ranta (1997) (i.e.: explicit correction, recast, clarification request, metalinguistic feedback, elicitation, and repetition), and Yao in Méndez et al. (2010) and Méndez \& Cruz (2012) (i.e.: Body language and facial expression) for collecting data on types of corrective feedback that students prefer to have. Of course, the characteristic of students and the class were the main consideration for choosing the types of correction that put in questionnaires, interview guide, and observation guide. For that reason, we referred to nine types of error correction to be investigated in this research. They are 1) Explicit correction, 2) Recast, 3) Clarification Request, 4) Meta-linguistic feedback, 5) Elicitation, 6) Repetition of Error, 7) Interruption, 8) Body Language, and 9) Transfer. Moreover, since the previous findings were done in different setting of research, there was a chance that this research revealed another type of error correction beside those nine types. We considered them as a finding and we also needed to investigate the reasons as well.

\section{METHODOLOGY}

This study applied Mixed Method because we need quantitative approach (i.e.: using questionnaire as the instrument) to gather data of students' preferences toward types of corrective feedback and qualitative approach to collect data of students' reasons for preferring particular types of corrective feedback through student interview and classroom observation. This study involved 196 students (from 385 students) of twelfth graders as the source of data for questionnaire, 68 students from classes (high and low proficiency class) as the source of data for observation and 10 students from the observed classes as the source of data for student interview.

We used three kinds of instruments; student questionnaire, student interview guide, and observation guide. At first, we did observation for three meetings in each class (i.e.: high and low proficiency class). We video recorded the three meetings and transcribed them for analysis. As well as interview, we conducted interview to ten interviewees after the observation had done. We prepared twenty-five questions based related to the reasons students preferred particular types of corrective feedback. The duration for each interviewee 
was about five to twelve minutes. All interviews were conducted in Bahasa Indonesia. We also recorded the interviews and transcribed them for analysis. We analyzed data of observation and interview transcript by using model of analyzing qualitative data proposed by Creswell (2008).

Furthermore, we used dichotomous questionnaire (Yes/No answer). There were three sections; 1) preferences on types of corrective feedback, 2) students' attitudes toward corrective feedback and 3) demographic questions. Overall, the questionnaire consisted of twenty-eight items; section 1 covered nine questions, section 2 covered twelve questions and section 3 covered seven questions. The questionnaires used in this study were the adaptation of Chaudron's (1988) error correction, Odalejo's (1993) questionnaire, Katayama's (2007), Yao's in Méndez et al. (2010) error correction, Lyster \& Ranta (1997) in Méndez et al. (2010) and Lyster \& Ranta (1997) error correction. Since the population was 369 students (it almost 400 students), so the amount of sample that we should take was 196 students with level of confidence 95\% (Research advisors, 2006). After validating and revising the questionnaire, we administered the questionnaires to 196 students of twelfth grade of SMK Negeri 1 Samarinda on $23^{\text {rd }}$ to $27^{\text {th }}$ September 2013. For data from questionnaires, we did simple calculation. It was by calculating how many students had answered "Yes" and "No" for each item of questionnaire. We, then, count the percentages and analyzed them by using frequency distribution analysis.

\section{FINDING}

\section{Observations}

From 373 minutes video transcript of three meetings each (high and low proficiency class), we found that, during three meetings in low proficiency class, there were found 155 errors occurred. Only $33 \%$ of the total errors were treated by the teacher and $2 \%$ of them were treated by student peers. The rest $(65 \%)$ of them were ignored. Meanwhile, teacher in high proficiency class treated $42 \%$ of total errors occurred (i.e.: 151 errors) and ignored $56 \%$ of them, and $2 \%$ of them were treated by peers. Overall, both teacher mostly treated teacher norms errors. Regarding to the types of corrective feedback that teachers used during the three meetings, we found that both teacher mostly used Recast to treat students' errors, followed by Loop (i.e.: Teacher ask student to repeat the error to ascertain the error), Combination (i.e.: Teacher used several type of corrective feedback to notice student's error) and Elicitation. After taking corrective feedback, students were able to repair the error 
correctly (LP class: 39\% (linguistically and 19\% correct in Teacher's norm but not linguistically; HP class: $50.7 \%$ linguistically). Moreover, we also found that the teachers themselves provided wrong remark when they gave correction. Especially in LP class, the teacher was lack of English knowledge, so that we provided more wrong remarks than the teacher in HP class

\section{Interview}

From the interview transcripts of ten interviewees, we found that most of students could accept corrective feedback because it made them know the location of their error. However, the acceptance of feedback may vary based on how the correction is given. Few students said that correction might make them feel nervous, dispersed concentration and feel embarrassed. Regarding to the timing of corrective feedback given, almost all students did not like immediate correction (i.e.: interruption) because it made them blank and forget what to say $(50 \%)$, dispersed concentration (40\%), afraid to continue speaking, confused and lessvalued (20\%), clumsy, nervous and awkward (10\%). In terms of students' preferences toward corrective feedback, students preferred to have explicit corrective feedback (50\%) because teachers provided more explanation on the location of error and the right version of errors, it was not puzzling, it was more detail and clearer so they can learn more. The other 50\% preferred to have implicit corrective feedback such as meta-linguistic clue because it made them think deeper (30\%), activate their knowledge and more capable in English (20\%), and feel challenged $(10 \%)$.

\section{Questionnaire}

From the result of questionnaire, we found that 97\% students preferred Explicit Correction, $87 \%$ preferred Meta-linguistic clue and $65 \%$ preferred Elicitation

\section{Discussion}

\section{Students' Preferences toward Corrective Feedbacks on Students' Oral Production}

Based on students' responses on questionnaires, they preferred to have 1) Explicit correction, 2) Meta-linguistic clue, 3) Elicitation, 4) Clarification Request, 5) Repetition, 6) Transfer, 7) Body Language and Facial Expression, 8) Recast, and 9) Interruption. It was consistent with Amador's (2008) finding that revealed explicit correction as the error correction techniques students preferred to have. Meanwhile, students' responses on interview showed that some of them (50\%) preferred explicit corrective feedback (Explicit and Recast) and the rest (50\%) preferred implicit corrective feedback (Elicitation, Metalinguistic Clue, Repetition, and Clarification Request). However, from the reasons they 
stated, they tended to explicit corrective feedback. There were seven reasons for preferring explicit correction and five reasons for preferring implicit correction.

Explicit and Recast included in explicit corrective feedback. It means that data from questionnaire and data from interview were matching each other, although Recast was in the eighth sequence in questionnaire result. Both data showed that students preferred explicit corrective feedback rather than implicit corrective feedback. However, since Explicit correction was liked the most, students still expected teachers' explanation for the reason why it was errors and how to repair them, besides, just giving the correct version directly. If students' preferences were related to their proficiency, both LP and HP students preferred Explicit correction and Meta-Linguistic clue. However, in terms of Elicitation, it seemed that LP students preferred Repetition rather than Elicitation. Otherwise, HP students preferred the contrary.

To know whether students' expectations met teachers' corrective feedback in the real class, we consulted these two data to observation data. From observation data, we found that both teachers used Recast most of the time. It consistent with previous finding, Jabbari \& Fazilatfar (2012) found that teachers mostly used Recast for EFL students at elementary level and high intermediate level. We believed that her finding was the same because of the same level of EFL students; it was elementary to intermediate level.

However, Mrs. E (LP class teacher) and Mr. Y (HP class teacher) still combined Recast with implicit corrective feedbacks. They used Recast after the students could not repair the error when they used implicit correction, such as Elicitation, Meta-linguistic Clue, Repetition, Confirmation and Transfer. We called this type as Combination (see excerpts 2736 and excerpts 142-166). Since, to treat one student's errors, they used more than one types of corrective feedback and they used to start it with implicit correction to let students selfrepair the error. After students gave up guessing the correct version, they gave explicit correction. It means that actually these teachers had met students' expectation in terms of using implicit correction such as Meta-linguistic clue and Elicitation. Nevertheless, they did not fulfill students' expectation in terms of using Recast. We can conclude that Mrs. E and Mr. Y had fulfilled students' expectation but not $100 \%$ in scale. In other words, they gave corrective feedback that students preferred to have but not for all types.

Furthermore, although students said implicit corrective feedback, a few students did not like Repetition too much since it puzzled them. Repetition made student feel that it just wasted time (P1. L70-L72) if students have lack of knowledge about the error and it just 
made them more confused (P10. L50-L57, L61-L65). Consulting to data of questionnaire, fifty five percent (107 respondents) liked it. Meanwhile, data of observation showed that Mrs. E did not give Repetition and Mr. Y gave it about 8\%. Data of interview and data of observation were matched since a few students did not expect it and teachers did not give it too much too. However, they did not match with data from questionnaire since in general; some of students (55\%) expected Repetition.

Moreover, based on interview responses, all students preferred if the teacher delivered corrective feedback after they had finished speaking. It means that students did not like Interruption. It also supported by data from questionnaire. It showed that 167 students (85\%) did not like CF. Interruption. Consulting these both data to the result of observation, Mr. Y and Mrs. E gave CF. Interruption but not too much. Mr. Y gave Interruption for $4 \%$ (5 cases) and Mrs. E gave it for $8 \%$ (6 cases) but one of them provided wrong remark.

Talking about Interruption, it dealt with the time of correction; immediate correction. Harmer (2001) had suggested teacher not to give immediate corrective feedback during fluency work. It would be better to wait until students had finished speaking. If we looked at the result of observation, Mrs. E had done six cases (8\%) of Interruption and Mr. Y had done five cases $(4 \%)$ of Interruption. It means that these teachers should not give Interruption when students were speaking. Since, as students said in interview, it made them confused, losing concentration, feeling unvalued and forgetting to say the next sentences.

Correcting students' oral work is not easy, especially, when teacher decides to give Interruption. It depends on the lesson objectives; for fluency or for accuracy. Harmer (2001) gave ways to treat students' error during fluency work. One of them was by doing gentle correction. It was the correction given when students could not continue to speak. Mrs. E seemed following this suggestion (See excerpt 34). We used Interruption to help the student continuing to speak. Meanwhile, Mr. Y seemed giving Interruption for 'silly' errors (i.e.: errors that students should not do because they have already mastered the rule) (see excerpt 160 and 166).

Moving to another implicit corrective feedback, although it was said that fifty percent interviewees like implicit corrective feedback, but when they asked about Body Language and Facial Expression (BLFE), eighty percent interviewees said they did not like it. Data of questionnaire also showed the same. It showed that only thirty percent students liked it. Data from observation also showed that BLFE was at the last rank of types of corrective feedback 
that teacher used. Mr. Y only gave it once during the three meetings of observation and Mrs. E did not give it at all. It can conclude that teachers matched students' expectation.

In addition, Transfer was included in the bottom four of students' preference toward corrective feedback. Transfer was the type of corrective feedback that students preferred to have in average. Data from interview showed that only three respondents liked it. Observation data showed that Mrs. E did not give any Transfer to treat students' errors. Meanwhile, Mr. Y gave Transfer to treat students' errors but not too much. He used CF. Transfer when the students could not answer his questions. There were seven cases $(6 \%)$ of Transfer. Considering the less number of students' preference toward Transfer in questionnaire and interview responses, only a few of students expected Transfer. If we traced back the interviewees, two of interviewees who expected CF. Transfer were from Mrs. E's class (P6 and P7: see appendix 12). In real condition, Mrs. E did not give any CF. Transfer at all. We did not match students' expectation. Meanwhile, Mr. Y gave Transfer but only one interviewee expected it. We believed that this related to students' English proficiency. P6 and P7 were from LP class (low proficiency class). P6 and P7 said that they felt comfortable and did not mind having CF. Transfer (P6. L70-L72; P7. L62-L63). P4 thought her other friends were better than her (P4. L91-L93). From the reasons they gave, we assumed that these students did not want to think deeper to self-correct their error. That was why they liked CF. Transfer.

In conclusion, matching expectation between students' preferences toward types of corrective feedback and the types of corrective feedback that teachers gave in the classroom would make the correction more effective (Odalejo, 1993). However, in the real situation, they do not always match. Just like what we found in her investigation, the type of corrective feedbacks that students preferred to have was Explicit. Although, it did not match with the types of corrective feedback that teachers used; it was Recast. It must bring some effect to students, such as, they were confused to repair the error. On the other hand, students also preferred Elicitation and Meta-Linguistic and teachers gave it although they combined them with explicit correction. It means that teachers met students' expectation. What is more, students did not like CF. Interruption, Transfer and BLFE too much, and teachers did not give them too much in real class. More and less, the teachers had met students' expectation for their preference toward particular types of corrective feedback, although not for all.

In addition, we found that Expansion as a new finding. P8 stated that we did not like that way since it made her confused. We said that teacher's correction had complicated her.

Script Journal Volume 1, Issue 1, April 2016 || ISSN 2477-1880 || E-ISSN 2502-6623 http://jurnal.fkip-uwgm.ac.id/index.php/Script 
In Expansion, teacher added or provided new expressions or new words for students to combine and/or to change the previous words/sentences. This expansion made the student confused to repair (P8. L24-L29). Usually, students understand teacher's correction after s/he gave more explanations and provided the correct version. Although it was not full sentence, they understood how to repair the error; it was by adding more sentences for the dialogue they had performed.

\section{Students' Reasons Preferring Explicit correction, Meta-Linguistic Clue and Elicitation}

As it mentioned above, students preferred to have explicit corrective feedback, especially Explicit. Explicit was preferred because it was not puzzling since teachers gave explanation as well (P1. L61-L65; P10. L49-L50). Besides, Explicit was more detail and clearer. It also made students could learn more (P6. L57-L58; P7. L44-L46). As a bonus, students did not have to wait to know the correct version because in implicit correction teacher took time for students to self-repair and finally they gave the correct version (P6. L56).

Moreover, five of interviewees preferred implicit correction. Students preferred Metalinguistic Clue and Elicitation because they made students think deeper (P2. L53-L58; P3. L71-L72; P9. L51). Moreover, Meta-linguistic Clue made students recall their knowledge and made them more capable in English (P3. L67-68; P8. L44-L46). In addition, these types of corrective feedback were challenging (P2. L54) and made them feel comfortable (P3. L70). However, students preferred implicit correction because explicit correction underestimated students' ability (P4. L68-L72).

\section{Students' Reasons for Their Lack of Interest on CF. Repetition and CF. Clarification Request.}

Repetition and Clarification Request have things in common. They both deal with repetition of error and indirect error notification. Students did not like Repetition and Clarification Request because they made students confused (P5. L50-L53) and these types just wasted time (teachers' and students' time) for waiting students' responses (P1. L70-L72). However, the acceptance toward these types depended on students' knowledge. If the student had lack of knowledge about the error, then implicit correction would be a problem for him/her because it just made him/her confused (P10. L50-L57, L61-L65). S/he could not selfrepair it although the teacher insisted. Therefore, explicit correction may be more effective

Script Journal Volume 1, Issue 1, April 2016 || ISSN 2477-1880 || E-ISSN 2502-6623 http://jurnal.fkip-uwgm.ac.id/index.php/Script 
for students who had lack of knowledge rather than giving them implicit corrective feedbacks.

\section{Students' Reasons for Their Lack of Interest on BLFE}

Still discussing about implicit corrective feedbacks that students did not preferred, BLFE was also the most disliked types of corrective feedback. Most of students did not like it because it was ineffective correction (P8. L72-L75) since they did not pay attention to teachers' body language and facial expression (P1. L79-L84). BLFE also made students confused (P5. L60) in knowing the location of the error (P4. L82-L83; P6. L66-L67; P7. L56L57; P8. L62-L63; P9. L68-L69; P10. L75), and how to repair their errors. Moreover, BLFE made students felt uncomfortable (P4. L79-L80; P8. L54), were afraid of making mistakes (P4. L84-L85) and made students could not continue to speak because of confusing correction (P8. L58-L59). In addition, students assumed the teacher as a less-communicative person (P2. L66).

\section{Students' Reasons for Their Lack of Interest on Transfer and Interruption}

Additionally, talking about Transfer, only three interviewees liked this type because it made students no need to think deeper (P4. L91-L93) and feel comfortable (P6. L70-L72; P7. L62-L63). However, students supposed that Transfer just wasted teachers' time to give students who have lack of knowledge to self-repair ((P1. L101-L103: P10. L91-L99). P10 said that if one student in her class did not know the correct version, then, as usual, none of students in that class knew it. So, it would be better if teacher just give them correction explicitly (P10. L84-L85, L91-L97). In other words, it was not efficient to treat students' errors by using CF. Transfer. Another four interviewees said they disliked Transfer because it made them did not know the location of error (P1. L95-L101), made them feel unappreciated since the teacher did not give chances to self-repair ((P1. L104-L107: P2. L86-L87: P3. L88L94: P8. L68-L70: P9. L84-L88), and made students felt like an incompetent person and worse than the other (P2. L79, L84-L85).

Moreover, Interruption was the most unwanted types of corrective feedback based on interview data. Data questionnaire also showed the same. Interruption was types of corrective feedback which given directly at the time students do errors. It was difficult for student to accept Interruption (P3. L35). Students disliked Interruption because it made them get blank and forget what they have to say next (P1. L43-L45; P3. L46-L49; P5. L36-L37; P6. L43L44; P10. L38-L40). In other words, it made students' concentration dispersed (P3. L50-L51; P5. L34; P6. L43-L46; P9. L38-L39). Moreover, it also made them confused (P2. L37-L38; 
P6. L37-L38), nervous (P6. L39-L40; P10. L 41-42), feel less valued (P3. L53-L54; P4. L47), clumsy and awkward (P9. L35, L41). Therefore, students expected teachers to delay the corrective feedback after they finished the sentence.

\section{Other Findings}

As it had been touched above, we found three findings that previous findings did not find. They were 1) six new types of corrective feedback, 2) Teacher's Norm Errors and 3) NNS teachers had chance to provide wrong remark since they are the sources of students' errors, too. Firstly, besides the nine types of corrective feedbacks that we proposed before, we found other six types from observation. They were 1) Expansion, 2) Explanation, 3) Loop, 4) Confirmation, 5) Combination and 6) Students' Example. In addition, in previous studies, teachers used to treat one student's error with one type of corrective feedback. However, in this study, we found that teachers used more than one types of corrective feedbacks to treat one student's error. It usually starts with implicit corrective feedback and ends with explicit corrective feedback. Therefore, we called this type as Combination.

Moreover, we found one type of errors. We called it Teacher's Norm Error. It is students' word or sentences that teachers think they are incorrect, such as, incomplete answer, unexpected answer, although, they are not deviant linguistic forms. The referent of the correct version of the errors is the teacher's norm. That is why we called it as Teacher's Norm Errors. Actually, Allwright \& Bailey (1991) had recognized it before. They said 'we find that learners' responses are sometimes rejected by teachers-not because they are wrong but because they are unexpected' Allwright \& Bailey (1991). This case occurred in second or foreign language classroom. That explained teacher's norm errors appeared in this research, because, for the observed classes, English is as foreign language.

In addition, since the teachers were Non Native Speaker, there always be chances for them to do errors, too. The teachers' English proficiency also became the cause of teachers as the source of students' error. As the result, teachers provided wrong correction. Unfortunately, students followed these errors and they assumed them as the correct versions in native speaker norm, since, teachers provided these errors while giving corrective feedback. As the result, teachers did not make students' errors becoming correct, but, unfortunately, they made them lost.

Script Journal Volume 1, Issue 1, April 2016 || ISSN 2477-1880 || E-ISSN 2502-6623

http://jurnal.fkip-uwgm.ac.id/index.php/Script 


\section{CONCLUSION}

As a conclusion, students preferred to have Explicit and some implicit corrective feedbacks like Elicitation, Meta-linguistic Clue. They liked Repetition, Clarification Request and Transfer but not too much. Students did not prefer to have Interruption and BLFE since they were confusing. Moreover, Students preferred Explicit because they could know the correct version of their error directly as well as teacher's explanation. In other words, Explicit was clearer than other types of corrective feedbacks. They preferred Elicitation and Metalinguistic Clue because they activated their knowledge and challenging. Moreover, they did not like Repetition and Clarification too much because they would make students confused if they did not have knowledge about the errors. For low-proficiency students, Transfer saved them from teachers' pressure to make them self-repairing the error, but for high proficiency students, Transfer made them feel unvalued because the teachers did not give them chance to self-repair. In addition, students did not preferred Interruption and BLFE because it made them confused to notice the location of their errors.

Besides the nine types of corrective feedbacks that students preferred to have, we found that teachers gave six more types of corrective feedbacks to treat students' errors. They were Expansion, Explanation, Loop, Confirmation, Students' example and Combination. In terms of Combination, we found that, teachers used more than one types of corrective feedback to treat one student's errors since students did not notice their error at the first corrective feedback given. Furthermore, teachers mostly treated teachers' norm errors. These errors were not deviant linguistic form but they called errors because teachers thought so. Finally, since teachers were also the source of students' errors, we found teachers provided wrong correct version of students' errors when they gave corrective feedbacks. Unfortunately, since the students were lack of English knowledge, too, they did not notice for the teachers' errors and followed them as the 'correct' version of their errors.

\section{BIBLIOGRAPHY}

Allwright, D., \& Bailey, K. (1991). Focus on the Language Classroom: An Introduction to Classroom Research for Language Teachers. Cambridge: Cambridge University Press.

Amador, Y. A. (2008). Learner Attitudes toward Error Correction in a Beginner English Class. Revista Communicación, 17(1), 18-28.

Brown, H. D. (2000). Principles of Language Learning and Teaching. New York: Longman.

Script Journal Volume 1, Issue 1, April 2016 || ISSN 2477-1880 || E-ISSN 2502-6623

http://jurnal.fkip-uwgm.ac.id/index.php/Script 
Chaudron, C. (1988). Second Language Classrooms. Research on Teaching and Learning. New York: Cambridge University Press.

Creswell, J. W. (2008). Educational Research. Planning, Conducting, and Evaluating Quantitative and Qualitative Research (3rd ed.). London: Pearson Prentice Hall.

Harmer, J. (2001). The Practice of English Language Teaching (3rd ed.). London: Longman.

Jabbari, A. A., \& Fazilatfar, A. M. (2012). The role of Error Types and Feedback in Iranian EFL Classrooms. International Journal of English Linguistics, 2(1), 135-148.

Katayama, A. (2007). Japanese EFL Students' Preferences toward Correction of Classroom Oral Errors. Asian EFL Journal, 9(4).

Lyster, R., \& Ranta, L. (1997). Corrective Feedback and Learner Uptake: Negotiation of Form in Communicative Classroom. New York: Cambridge University Press.

Méndez, E., Arguelles, L., \& Castro, A. (2010). Oral Corrective Feedback: Some Ways to Go About it. Meorias Del ViForo De Estudios En Lenguas Internacional, 254-270.

Méndez, E., \& Cruz, M. (2012). Teacher's Perceptions about Oral Corrective Feedback and Their Practice in EFL Classroom. PROFILE, 14(2), 63-75.

Odalejo, J. (1993). Error Correction in ESL: Learners' Preferences. TESL Canada Journal/Revues TESL Du Canada, 10(2), 71-87.

Ortega, L. (2009). Understanding Second Language Acquisition. Oxford: Hodder Education.

Rahimi, A., \& Dastjerdi, H. (2012). Impact of Immediate and Delayed Error Correction on EFL Learners' Oral Production: CAF. Mediterranean Journal of Social Sciences, 3(1), 45-54.

Research advisors. (2006). Sample size Table.

Ur, P. (1996). A Course in Language Teaching. Cambridge: Cambridge University Press. 